\title{
Nonlinear Creep Model of Deep Gangue Backfilling Material and Time-Dependent Characteristics of Roof Deformation in Backfilling Mining
}

\author{
Peng Huang, ${ }^{1,2}$ Jixiong Zhang $\mathbb{D}^{1,2}$ Qi Zhang $\mathbb{D}^{1,2}$ Ntigurirwa Jean Damascene $\mathbb{D}^{1,2}$ \\ and Yuming Guo ${ }^{1,2}$ \\ ${ }^{1}$ School of Mines, China University of Mining and Technology, Xuzhou 221116, China \\ ${ }^{2}$ State Key Laboratory of Coal Resources and Safe Mining, China University of Mining \& Technology, Xuzhou 221116, China \\ Correspondence should be addressed to Jixiong Zhang; cumtzjxiong@163.com and Qi Zhang; zhangqi8965068@163.com
}

Received 13 August 2020; Revised 5 October 2020; Accepted 24 October 2020; Published 18 November 2020

Academic Editor: Zhijie Wen

Copyright (C) 2020 Peng Huang et al. This is an open access article distributed under the Creative Commons Attribution License, which permits unrestricted use, distribution, and reproduction in any medium, provided the original work is properly cited.

\begin{abstract}
With the gradual increase in mining depth of coal resource exploitation, deep backfilling mining has effectively solved the impact of strong deep mine pressure and strong mining disturbances. However, after deep backfilling mining, the backfilling material is subjected to high stress for a long time, and its viscoelasticity has a significant impact on the roof control effect. This paper uses a large-scale bulk confinement test device to analyze the viscoelastic properties of gangue, establishes a high-precision fractional viscoelastic creep model, and identifies the gangue parameters. The established fractional viscoelastic model was used as the foundation model of the beam, and the roof model based on the fractional viscoelastic foundation was solved. The top deformation characteristics of elastic foundation and fractional foundation were compared and analyzed, and the time effect, viscoelastic effect, and order effect of the fractional order viscoelastic foundation beam were discussed. The results show that the viscosity of gangue increased under the action of deep high stress. As time increased, the roof deformation also increased. In order to more effectively control the long-term deformation of the roof, the viscosity coefficient of the backfilling material should be greater than $20 \mathrm{MPa}$. This research provides relevant guidance for the requirements of backfilling materials for deep backfilling mining and the prediction of long-term dynamic deformation of the roof in underground excavations.
\end{abstract}

\section{Introduction}

As the mining depth increases for coal resources exploitation, deep backfilling mining technology has achieved considerable development in China and has achieved significant economic, social, and environmental benefits in many mining areas [1]. Due to the fundamental changes of the environment in deep mining, the surrounding rock environment of the gangue backfill body will face the conditions of high ground stress, high water pressure, and strong mining disturbances, which will inevitably affect the internal void structure and mechanical properties of gangue and long-term deformation characteristics $[2,3]$. Under the above-mentioned complicated deep environmental conditions, the mechanical properties of the rock are significantly different from those under the shallow in situ stress state. The specific manifesta- tion is that the rock mass under high stress in the deep has continuous strong rheological properties [4]. In addition, deep rock mass is prone to brittle-ductile transformation, and its failure shows strong plastic deformation characteristics [5]. The gangue backfill body is used as a medium to prevent the deformation of the rock formation [6]. The mechanical properties, especially the long-term rheological and viscoplastic properties under the above-mentioned high stress-water environmental conditions, are very important for the roof control and backfilling effect.

Scholars worldwide have carried out many researches on backfilling material properties and solid backfilling mining. Zhang et al. [7] studied the distribution and characteristics of granular materials, cement materials and higher water content materials, and a guide for the selection of backfilling materials. The finite compression 
experiment was conducted to analyze the deformation and crushing characteristics of the gangue bulk materials under different water immersion heights by Li et al. [8]. Li et al. [9] tested compaction properties of crushed gangue backfilling materials with different particle sizes and also analyzed the influences of particle size of the backfilling materials on surface subsidence. Huang et al. [10] analyzed the mesostructure, stress variation, energy dissipation, and backfilling effects of the five common solid backfilling materials. In addition, the time-dependent characteristics of gangue and other backfilling materials are also a hot subject of research. Researches showed that gangue creep has viscoelastic properties [11-15]. Moreover, the viscoelastic properties of gangue also have an important impact on the deformation of the roof of the backfilled space in backfilling mining [16-19]. However, many roof models of solid backfilling mining are based on elastic foundation assumptions, ignoring the viscoelasticity of the backfilling materials [20-24].

Fractional calculus is a branch of mathematics. As an excellent mathematical tool, it has been successfully applied in fields such as rheology, electromagnetics, signal processing, and chaotic systems [25]. Abel dashpot based on fractional derivative, showing the characteristics of Spring and Newtonian dashpot, with viscoelastic characteristics. Some classic viscoelastic models, such as the Maxwell model, Kelvin-Voigt model, and general Kelvin-Voigt model, are improved by using the fractional Abel dashpot [26-28]. Those fractional viscoelastic models have much better advantages for describing the material's rheological mechanical properties than the integer-order calculus [29].

This paper uses a large-scale confined compression test device to study the creep characteristics of gangue and establishes a high-precision fractional viscoelastic creep model of gangue. The fractional viscoelastic creep model is used as the foundation of the beam, and the fractional viscoelastic foundation roof model is also established. The deformation, viscoelastic effect, and time effect of the backfilling mining roof are analyzed. This research can be used to predict the dynamic subsidence of the deep backfilling mining roof and provides relevant theoretical guidance for rock strata longterm deformation.

\section{Gangue Creep Test}

2.1. Sample and Testing Procedure. The particle size range of gangue is $0-30 \mathrm{~mm}$, from the Pingdingshan coal mines, which matches the actual gradation of gangue in the goaf. The main lithology of gangue materials is mudstone with an average density of $1450 \mathrm{~kg} \cdot \mathrm{m}^{-3}$ and a moisture content of $0.42 \%$. The X-ray diffraction (XRD) results show that mudstone mainly consists of $37.36 \%$ quartz, 34.23\% kaolinite, $11.22 \%$ illite, $2.11 \%$ chlorite, $1.15 \%$ feldspar, and other minerals. The YAS-5000 electrohydraulic servocontrolled rock mechanic test system was employed for the backfilling material compaction tests. The compacted steel barrel is a cylindrical compacted steel barrel designed by the authors, including the loading platen, handle, bolt and base, as shown in Figure 1. The steel barrel's inner diameter is $250 \mathrm{~mm}$, height is $305 \mathrm{~mm}$, and yield limit is $235 \mathrm{MPa}$. The uniaxial creep tests were performed on gangue materials by using the steel circular cylinder, for constant loads of $5 \mathrm{MPa}$, $10 \mathrm{MPa}, 15 \mathrm{MPs}$, and $20 \mathrm{MPa}$ stress in the axial direction for $60 \mathrm{mins}$ each, and with a loading rate of $1 \mathrm{kN} / \mathrm{s}$.

2.2. Testing Result. The relationships between strain and time, deformation rate, and time of gangue under four different axial pressures are shown in Figure 2.

As shown in Figure 2, the deformation of gangue is not linear with time in lateral confined creep tests. With the increase of axial pressure, the creep strain of gangue reduces gradually, such as $\Delta \varepsilon_{1}, \Delta \varepsilon_{2}$, and $\Delta \varepsilon_{3}$. The deformation of gangue can be divided into two stages: deceleration deformation and stable deformation, which clearly defines the viscoelastic properties of gangue. Therefore, when predicting the long-term deformation of gangue, the viscoelastic characteristics should not be ignored.

\section{Gangue Material Creep Model and Parameter Identification}

In order to study the viscoelastic characteristics of the gangue creep process, it is necessary to establish a highprecision creep model. The fractional calculus theory has obvious advantages in the accuracy and prediction of the creep model [30-32].

\subsection{Fractional Viscoelastic Creep Model}

3.1.1. Basic Concept of Fractional Calculus. The $n$th derivative of a function $f(t)$ is expressed as $D^{\alpha} f(t)=d^{\alpha} f(t) / d t^{\alpha}$. If $\alpha$ is a fraction, this expression becomes a fractional derivative. Fractional calculus is usually expressed in terms of the Riemann-Liouville definition. The Riemann-Liouville fractional integration of function $f(t)$ of order $\alpha$ is defined as [33]

$$
D_{t}^{-\alpha} f(t)=\frac{1}{\Gamma(\alpha)} \int_{0}^{t}(t-\xi)^{\alpha-1} f(\xi) d \xi \quad(\operatorname{Re}(\alpha)>0, t>0)
$$

where 0 and $t$ are the limits of integration at the left and right sides of $D ; \Gamma(\alpha)$ is the gamma function with argument $\alpha$, which is defined by

$$
\Gamma(\alpha)=\int_{0}^{\infty} e^{-t} t^{\alpha-1} d t \quad(\operatorname{Re}(\alpha)>0)
$$

The fractional derivative is defined by

$$
D^{\alpha} f(t)=\frac{d^{n}\left[D^{-(n-\alpha)} f(t)\right]}{d t^{n}}
$$

where $\alpha \geq 0, n-1 \leq \alpha \leq n$, and $n$ are positive integers.

3.1.2. Abel Dashpot. $\mathrm{AD}$ is a component derived from the integer-order creep element, as shown in Figure 2. 


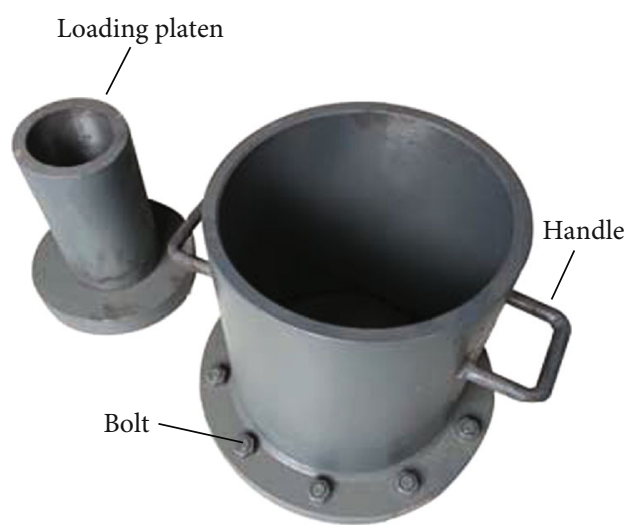

(a) Compacted steel barrel

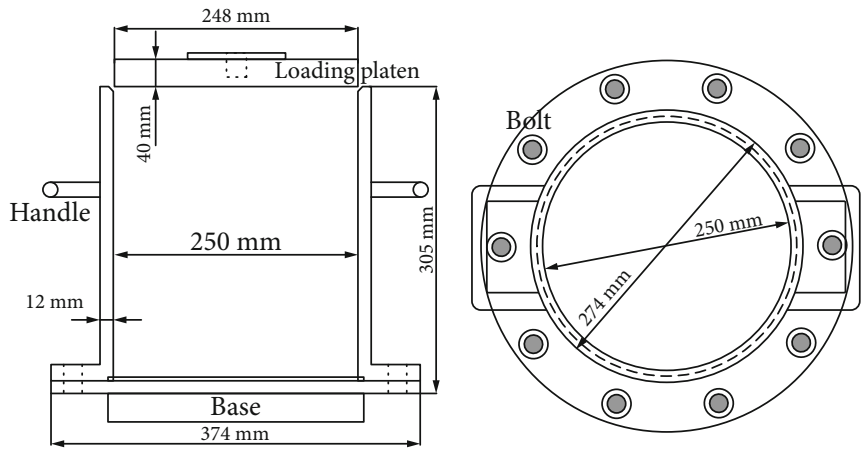

(b) Dimensions

FIGURE 1: Compacted steel barrel and dimensions.

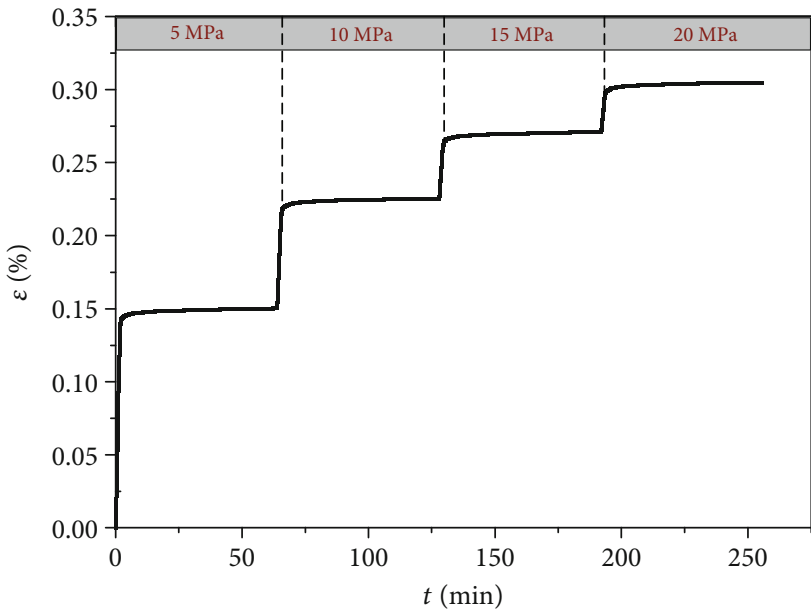

(a) Relationships between strain and time

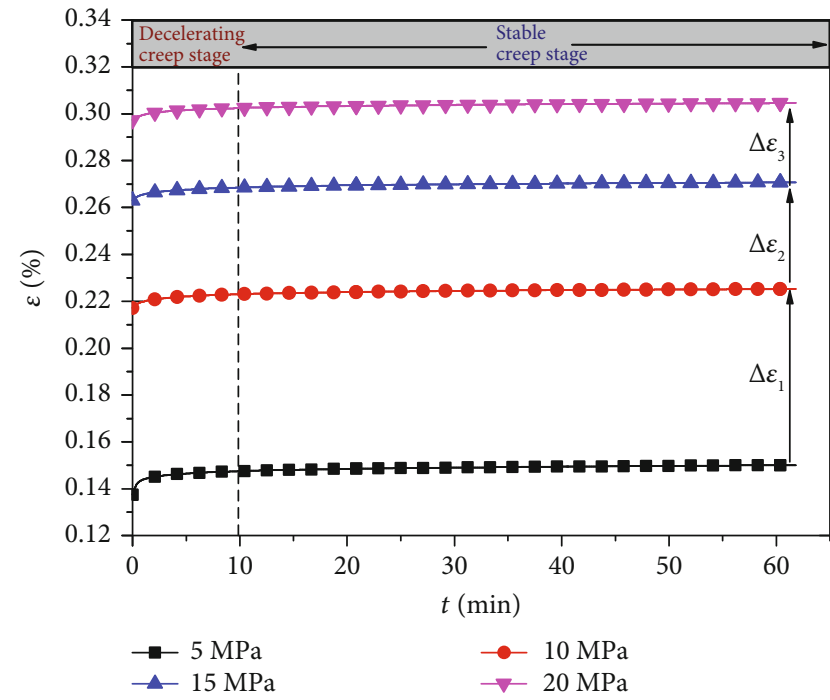

(b) Relationships between deformation rate and time

FIGURE 2: Gangue creep properties.

AD's stress and strain have the following expressions:

$$
\begin{aligned}
& \sigma(t)=\eta_{c} \frac{d^{\alpha} \varepsilon(t)}{d t^{\alpha}} \quad\left(0 \leq \alpha \leq 1, \alpha \in R^{+}, t>0\right), \\
& \varepsilon(t)=\frac{\sigma_{c}}{\eta} \frac{t^{\alpha}}{\Gamma(\alpha+1)} \quad\left(0 \leq \alpha \leq 1, \alpha \in R^{+}, t>0\right),
\end{aligned}
$$

where $\alpha$ is the fractional order; $t$ is the time, $\mathrm{h} ; \eta_{c}$ is the coefficient of viscosity; $\sigma$ is the stress, $\mathrm{MPa} ; \sigma_{c}$ is the constant stress, $\mathrm{MPa}$; and $\varepsilon$ is the strain.

According to formula (5), given the relevant mechanical parameters of the material, the creep characteristic curves under different orders are obtained, as shown in Figure 3.

It can be seen from Figure 3 that under the condition of constant stress, as $\alpha$ increases, the corresponding strain rate increases; when $\alpha$ is a fractional order, the strain curve increases slowly, rather than linearly like Newtonian fluid increase. However, the elastic body strain remains unchanged; the creep of the material shows a nonlinear grad- ual process, indicating that the properties of the material are between fluid and solid; and the fractional viscous pot can well reflect the viscoelastic properties of the material.

3.1.3. Fractional Poynting-Thomson Model. According to the viscoelastic relationship of the gangue creep experiment, the fractional Poynting-Thomson model is selected as the viscoelastic foundation model of gangue. The model consists of a fractional Maxwell model with elastic elements in parallel, as shown in Figure 4.

The constitutive relationship of each element in the fractional Maxwell model is

$$
\left\{\begin{array}{l}
\sigma_{1}=E_{1} \varepsilon_{1}(t), \\
\sigma_{1}=\eta^{\alpha} D^{\alpha}\left[\varepsilon_{2}(t)\right] .
\end{array}\right.
$$

According to the series relationship,

$$
\varepsilon(t)=\varepsilon_{1}(t)+\varepsilon_{2}(t)
$$




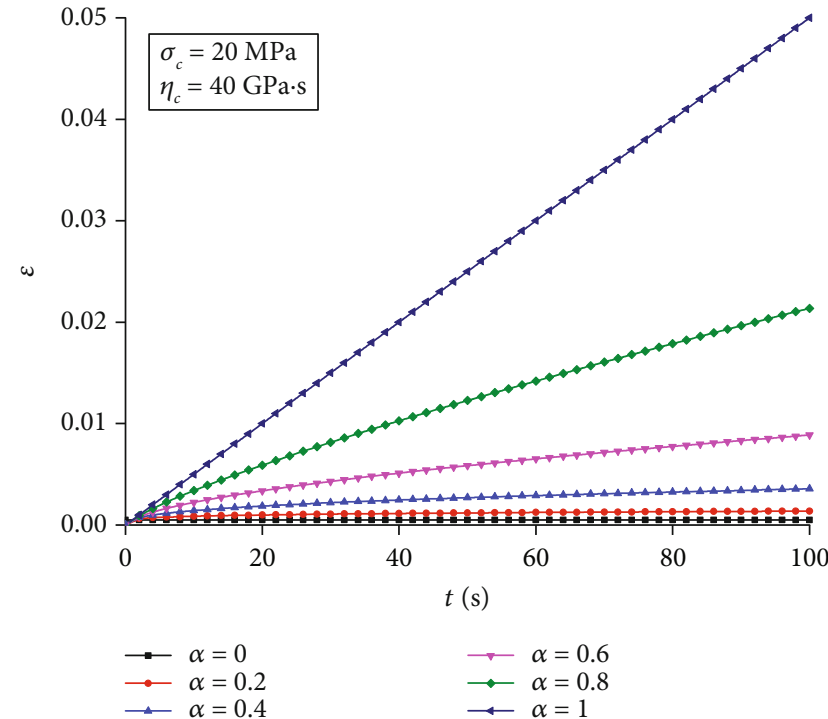

FigURE 3: Effect of different orders of $\alpha$ on creep properties.

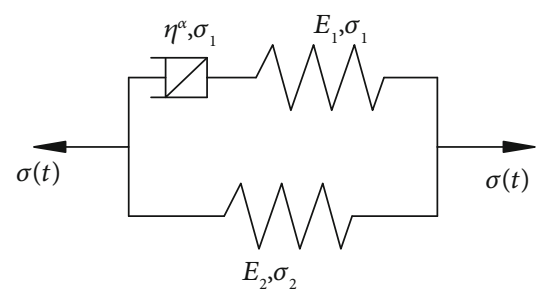

FIgure 4: Fractional Poynting-Thomson model.

Laplace transformation is carried out on formula (6) and substituted into formula (7):

$$
E_{1} \eta^{\alpha} s^{\alpha} \bar{\varepsilon}(s)=\eta^{\alpha} s^{\alpha} \overline{\sigma_{1}}(s)+E_{1} \overline{\sigma_{1}}(s)
$$

Carrying out the Laplace inverse transformation on formula (8), the constitutive relationship of Maxwell model can be obtained as

$$
E_{1} \eta^{\alpha} D^{\alpha}[\varepsilon(t)]=\eta^{\alpha} D^{\alpha}\left[\sigma_{1}(t)\right]+E_{1} \sigma_{1}(t) .
$$

When $\sigma_{1}(t)=\sigma_{0}$, Laplace transformation and inverse transformation were performed on equation (9), and the creep relationship of Maxwell model can be obtained as

$$
\varepsilon(t)=\frac{\sigma_{0}}{E_{1}}+\frac{\sigma_{0}}{\eta^{\alpha}} \frac{t^{\alpha}}{\Gamma(\alpha+1)} .
$$

The constitutive relationship of each element in the fractional Poynting-Thomson model is

$$
\left\{\begin{array}{l}
D^{\alpha}\left[\sigma_{1}(t)\right]+\frac{E_{1}}{\eta^{\alpha}} \sigma_{1}(t)=E_{1} D^{\alpha}\left[\varepsilon_{1}(t)\right], \\
\sigma_{2}(t)=E_{2} \varepsilon_{2}(t) .
\end{array}\right.
$$

From the parallel relationship and the Laplace transformation of equation (11),

$$
\eta^{\alpha} s^{\alpha} \bar{\sigma}(s)+E_{1} \bar{\sigma}(s)=E_{1} \eta^{\alpha} s^{\alpha} \bar{\varepsilon}(s)+E_{1} E_{2} \bar{\varepsilon}(s)+E_{2} \eta^{\alpha} s^{\alpha} \bar{\varepsilon}(s) .
$$

Carrying out the Laplace inverse transformation on formula (12), the constitutive relationship of the fractional Poynting-Thomson model can be obtained as

$$
\sigma(t)+\frac{\eta^{\alpha}}{E_{1}} D^{\alpha}[\sigma(t)]=E_{2} \varepsilon(t)+\left(\eta^{\alpha}+\frac{E_{2} \eta^{\alpha}}{E_{1}}\right) D^{\alpha}[\varepsilon(t)] .
$$

When $\sigma_{1}(t)=\sigma_{0}$, Laplace transformation was performed on equation (13) to obtain

$$
\bar{\varepsilon}(s)=\frac{E_{1} \sigma_{0}}{\left[E_{1} E_{2}+\left(E_{1}+E_{2}\right) \eta^{\alpha} s^{\alpha}\right] s}+\frac{\eta^{\alpha} \sigma_{0}}{\left[E_{1} E_{2} s^{1-\alpha}+\eta^{\alpha}\left(E_{1}+E_{2}\right) s\right]} .
$$

After proving the formula (14), formula (15) was obtained:

$$
\bar{\varepsilon}(t)=\frac{E_{1} \sigma_{0}\left(E_{1}+E_{2}\right)^{-1} \eta^{-\alpha} s^{-1}}{E_{1} E_{2} /\left(E_{1}+E_{2}\right) \eta^{\alpha}+s^{\alpha}}+\frac{\sigma_{0}\left(E_{1}+E_{2}\right)^{-1} s^{\alpha-1}}{E_{1} E_{2} / \eta^{\alpha}\left(E_{1}+E_{2}\right)+s^{\alpha}} .
$$

The Laplace variation expression of the two-parameter Mittag-Leffler function is

$$
\int_{0}^{\infty} e^{-s t} t^{\alpha k+\beta-1} E_{\alpha, \beta}^{(k)}\left( \pm a t^{\alpha}\right) d t=\frac{k ! s^{\alpha-\beta}}{\left(s^{\alpha} \mp a\right)^{k+1}} \quad\left(\operatorname{Re}(p)>|a|^{1 / \alpha}\right) .
$$

Carrying out Laplace inverse transformation on equation (15) from equation (16), the creep relationship of the fractional Poynting-Thomson model can be obtained as

$$
\begin{aligned}
\varepsilon(t)= & \frac{E_{1} \sigma_{0}}{\left(E_{1}+E_{2}\right) \eta^{\alpha}} t^{\alpha} E_{\alpha, \alpha+1}\left(-\frac{E_{1} E_{2}}{\left(E_{1}+E_{2}\right) \eta^{\alpha}} t^{\alpha}\right) \\
& +\frac{\sigma_{0}}{\left(E_{1}+E_{2}\right)} E_{\alpha, 1}\left(-\frac{E_{1} E_{2}}{\left(E_{1}+E_{2}\right) \eta^{\alpha}} t^{\alpha}\right) .
\end{aligned}
$$

3.2. Fractional Poynting-Thomson Model Parameter Identification. The expression of generalized Hookes law in three-dimensional form is as follows:

$$
\left\{\begin{array}{l}
\varepsilon_{m}=\frac{\sigma_{m}}{3 K}, \\
e_{i j}=\frac{S_{i j}}{2 G}
\end{array}\right.
$$

where $\sigma_{m}$ is the first invariant of the stress tensor, $\mathrm{MPa} ; \varepsilon_{m}$ is the first invariant of strain tensor; $S_{i j}$ is the deviatoric stress 
tensor, $\mathrm{MPa} ; e_{i j}$ is the deviatoric strain tensor; $K$ is the bulk modulus, GPa; and $G$ is the shear modulus, GPa.

Usually, when the rock is in the three-dimensional stress state, the spherical stress tensor will cause the volume deformation of the element without changing its shape, while the deviatoric stress tensor causes element shape change without volume change. The expressions of stress state and strain state are as follows:

$$
\left\{\begin{array}{l}
\sigma_{i j}=\sigma_{m} \delta_{i j}+S_{i j}, \\
\varepsilon_{i j}=\varepsilon_{m} \delta_{i j}+e_{i j},
\end{array}\right.
$$

where $\sigma_{m} \delta_{i j}$ is the spherical stress tensor in $\mathrm{MPa}$ and $\varepsilon_{m} \delta_{i j}$ is the spherical strain tensor.

Therefore, the strain expression of elastomer is

$$
\varepsilon_{i j}^{e}=\frac{S_{i j}}{2 G}+\frac{\sigma_{m} \delta_{i j}}{3 K} .
$$

In the elastic state, assuming that the spherical strain tensor and deviatoric strain tensor are related to the deviatoric stress tensor, respectively, the three-dimensional expression of the fractional Poynting-Thomson model is

$$
\begin{aligned}
\varepsilon(t)= & \frac{G_{1} S_{i j}}{2\left(G_{1}+G_{2}\right) \eta^{\alpha}} t^{\alpha} E_{\alpha, \alpha+1}\left(-\frac{G_{1} G_{2}}{\left(G_{1}+G_{2}\right) \eta^{\alpha}} t^{\alpha}\right) \\
& +\frac{S_{i j}}{2\left(G_{1}+G_{2}\right)} E_{\alpha, 1}\left(-\frac{G_{1} G_{2}}{\left(G_{1}+G_{2}\right) \eta^{\alpha}} t^{\alpha}\right),
\end{aligned}
$$

with the confining pressure and axial pressure having the following relationship:

$$
\sigma_{1}=\lambda \sigma_{2}=\lambda \sigma_{3} .
$$

Therefore, the three-dimensional creep equation of gangue under constant pressure in the steel drum is expressed as follows:

$$
\begin{aligned}
\varepsilon(t)= & \frac{G_{1} \sigma_{1}(1-\lambda)}{3\left(G_{1}+G_{2}\right) \eta^{\alpha}} t^{\alpha} E_{\alpha, \alpha+1}\left(-\frac{G_{1} G_{2}}{\left(G_{1}+G_{2}\right) \eta^{\alpha}} t^{\alpha}\right) \\
& +\frac{\sigma_{1}(1-\lambda)}{3\left(G_{1}+G_{2}\right)} E_{\alpha, 1}\left(-\frac{G_{1} G_{2}}{\left(G_{1}+G_{2}\right) \eta^{\alpha}} t^{\alpha}\right) .
\end{aligned}
$$

There are usually two methods to determine the parameters of the creep model. One is the graphical method, according to the relationship between the creep curve and the physical meaning [34], and another method is the optimization analysis method, such as the nonlinear least square method, which is widely used $[35,36]$. In this paper, the widely used Levenberg-Marquardt nonlinear least square method is adopted for parameter identification, as shown in Table 1.

In order to verify the validity of the creep model parameters, the comparison between the creep test data of gangue and the model curve is shown in Figure 5. It can be seen from the figure that the fractional Poynting-Thomson model is in
Table 1: Parameters of fractional Poynting-Thomson model.

\begin{tabular}{lccccc}
\hline$\sigma_{1}(\mathrm{MPa})$ & $G_{1}(\mathrm{MPa})$ & $G_{2}(\mathrm{MPa})$ & $\eta(\mathrm{MPa} \cdot \mathrm{min})$ & $\alpha$ & $R^{2}$ \\
\hline 5.0 & 3.1 & 0.56 & 44.67 & 0.21 & 0.99 \\
10.0 & 3.97 & 0.74 & 98.96 & 0.19 & 0.99 \\
15.0 & 4.86 & 1.13 & 68.21 & 0.11 & 0.99 \\
20.0 & 5.75 & 1.25 & 100.00 & 0.11 & 0.99 \\
\hline
\end{tabular}

good agreement with the experimental data, and the accuracy and $R^{2}$ are above 0.99 .

\section{Roof Mechanics Model of Backfilling Mining Space Based on Fractional Viscoelastic Foundation}

4.1. Mechanical Model of Fractional Viscoelastic Foundation Beam. The basic roof in solid backfilling coal mining can be regarded as a fixed beam on both sides supported by the upper part of the overlying rock load $q(x)$ and the lower part supported by the foundation reaction force $p(x)$, and the deflection of the beam section is expressed as $w(x)$ as shown in Figure 6. The working strike direction is established to be the positive $x$ direction, the direction of inclination to be the positive $y$ direction, and the vertical direction to be the positive $z$ direction.

4.2. Solution of Integer Order Solution of Elastic Foundation. Suppose the basic differential equation of elastic foundation beam deflection curve is

$$
E I \frac{d^{4} w(x)}{d x^{4}}=q(x)-p(x)
$$

When the foundation is an elastic foundation, the expression of $p(x)$ is given by

$$
p(x)=k_{0} w(x),
$$

where $k_{0}$ is the elastic foundation coefficient which can be obtained by the following formula:

$$
k_{0}=\frac{E_{0}}{h_{0}} .
$$

$E_{0}$ is the elastic modulus of the cushion, GPa; $h_{0}$ is the thickness of the cushion, $\mathrm{m}$.

The relationship among the corner $\theta$, the bending moment $M$, the shear force $Q$, and the deflection $w(x)$ of the beam section is

$$
\left\{\begin{array}{l}
\theta(x)=\frac{d w(x)}{d x} \\
M(x)=-E I \frac{d^{2} w(x)}{d x^{2}}, \\
Q(x)=-E I \frac{d^{3} w(x)}{d x^{3}} .
\end{array}\right.
$$




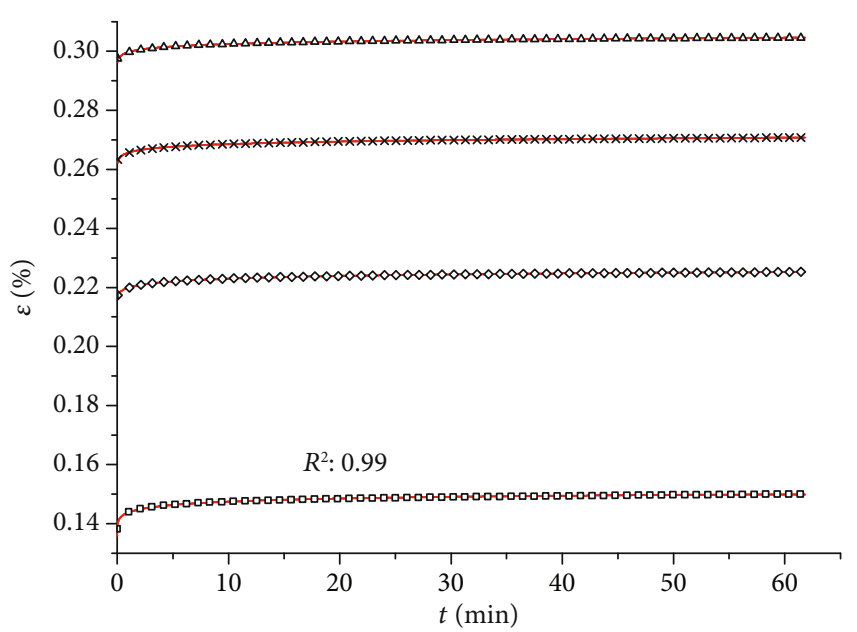

Test data:

$5 \mathrm{MPa}$

$\times 15 \mathrm{MPa}$

$\diamond 10 \mathrm{MPa}$

— Fractional Poynting-Thomson model curve

Figure 5: Fractional Poynting-Thomson model.
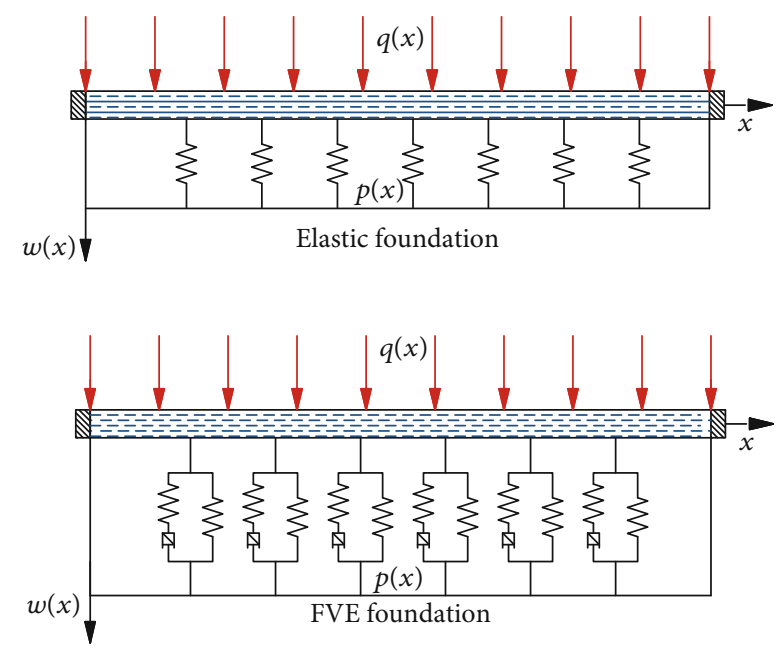

FIGURE 6: Fractional viscoelastic and elastic foundation beam.

Taking characteristic coefficients as $\alpha_{0}=\sqrt[4]{k / 4 E I}$, when the gangue backfilling material is regarded as an elastic material, the deflection curve equation of the roof beam can be obtained by solving equation (24):

$$
\begin{aligned}
w(x)= & e^{\alpha_{0} x}\left(d_{1} \sin \alpha_{0} x+d_{2} \cos \alpha_{0} x\right) \\
& +e^{-\alpha_{0} x}\left(d_{3} \sin \alpha_{0} x+d_{4} \cos \alpha_{0} x\right)+\frac{q_{0}}{k_{0}},
\end{aligned}
$$

where the $d_{1}, d_{2}, d_{3}$, and $d_{4}$ are the parameters.

4.3. Solution of Fractional Viscoelastic Foundation. From the constitutive relationship of the fractional Poynting-Thomson model (13), the relationship between the stress and deformation of the viscoelastic foundation is given by

$$
\left(\frac{\eta^{\alpha}}{E_{1}} D^{\alpha}+1\right) p(x, t)=\left[E_{2}+\left(\eta^{\alpha}+\frac{E_{2} \eta^{\alpha}}{E_{1}}\right) D^{\alpha}\right] \mathrm{w}(x, t) .
$$
as

Laplace transformation of equation (24) can be expressed

$$
E I \frac{d^{4} \bar{w}(x, s)}{d x^{4}}+\bar{k}_{0}(s) \cdot \bar{w}(x, s)=\frac{q_{0}}{s} .
$$

Laplace transformation of equation (13) can obtain the Laplace relationship between foundation reaction force and deformation as follows:

$$
\bar{p}(x, s)=\frac{E_{1} E_{2}+\left(E_{1}+E_{2}\right) s^{\alpha} \eta^{\alpha}}{\left(E_{1}+s^{\alpha} \eta^{\alpha}\right) h_{0}} \bar{w}(x, s) .
$$

From equation (29) and equation (31), the corresponding relationship between elastic foundation and viscoelastic foundation is derived and expressed as

$$
\left\{\begin{array}{l}
\sigma(t)\left(\frac{1}{t^{2}}+D^{\alpha}\right)=\varepsilon(t) E_{2} \eta^{\alpha} \tau^{\alpha}\left[1+\left(\frac{\eta^{\alpha}}{E_{2}}+\frac{\eta^{\alpha}}{E_{1}}\right) D^{\alpha}\right], \\
\bar{k}_{0}(s)=\frac{E_{1} E_{2}+\left(E_{1}+E_{2}\right) s^{\alpha} \eta^{\alpha}}{\left(E_{1}+s^{\alpha} \eta^{\alpha}\right) h_{0}} .
\end{array}\right.
$$

From equation (28), when the foundation is an elastic material, the Laplace expression of the bending deflection equation of the thin plate is

$$
\begin{aligned}
\bar{w}(x, s)= & e^{\alpha_{0} x}\left(d_{1} \sin \alpha_{0} x+d_{2} \cos \alpha_{0} x\right) \\
& +e^{-\alpha x}\left(d_{3} \sin \alpha x+d_{4} \cos \alpha_{0} x\right)+\frac{q_{0}}{\bar{k}_{0} \cdot s} .
\end{aligned}
$$

Substituting formula (32) into (33), the Laplace deflection equation of the viscoelastic foundation sheet becomes

$$
\begin{aligned}
\bar{w}(x, s)= & e^{\alpha_{0} x}\left(d_{1} \sin \alpha_{0} x+d_{2} \cos \alpha_{0} x\right) \\
& +e^{-\alpha x}\left(d_{3} \sin \alpha_{0} x+d_{4} \cos \alpha_{0} x\right) \\
& +\frac{q_{0}}{\left(E_{1} E_{2}+\left(E_{1}+E_{2}\right) s^{\alpha} \eta^{\alpha}\right) /\left(E_{1}+s^{\alpha} \eta^{\alpha}\right) h_{0} \cdot s} .
\end{aligned}
$$

By arranging the formula (34) to its final form, we can get

$$
\begin{aligned}
\bar{w}(x, s)= & e^{\alpha_{0} x}\left(d_{1} \sin \alpha_{0} x+d_{2} \cos \alpha_{0} x\right) \\
& +e^{-\alpha_{0} x}\left(d_{3} \sin \alpha_{0} x+d_{4} \cos \alpha_{0} x\right) \\
& +q_{0} h_{0} \frac{s^{-1}\left(E_{1}+s^{\alpha} \eta^{\alpha}\right) \cdot\left(E_{1}+E_{2}\right)^{-1} \eta^{-\alpha}}{E_{1} E_{2} /\left(E_{1}+E_{2}\right) \eta^{\alpha}+s^{\alpha}} .
\end{aligned}
$$


TABLE 2: Parameters of fractional viscoelastic foundation beam.

\begin{tabular}{lcccc}
\hline Foundation model & $d_{1}$ & $d_{2}$ & $d_{3}$ & $d_{4}$ \\
\hline Elastic (integer order) & 0.000861 & 0.000165 & -0.126192 & -0.125165 \\
Fractional order viscoelastic & 0.001171 & 0.001911 & -0.142520 & -0.139436 \\
\hline
\end{tabular}

Separating the variables from equation (35) and extracting the common factor, we get

$$
\begin{aligned}
\bar{w}(x, s)= & e^{\alpha_{0} x}\left(d_{1} \sin \alpha_{0} x+d_{2} \cos \alpha_{0} x\right) \\
& +e^{-\alpha x}\left(d_{3} \sin \alpha_{0} x+d_{4} \cos \alpha_{0} x\right)+\frac{q_{0} h_{0}}{\left(E_{1}+E_{2}\right) \eta^{\alpha}} \\
& \cdot\left[\frac{E_{1} s^{-1}}{E_{1} E_{2} /\left(E_{1}+E_{2}\right) \eta^{\alpha}+s^{\alpha}}+\frac{\eta^{\alpha} s^{\alpha-1}}{E_{1} E_{2} /\left(E_{1}+E_{2}\right) \eta^{\alpha}+s^{\alpha}}\right] .
\end{aligned}
$$

Carrying out the Laplace inverse transformation of equation (36) and introducing the two-parameter Mittag-Leffler function, the deflection equation of the viscoelastic foundation sheet can be obtained as

$$
\begin{aligned}
w(x, t)= & e^{\alpha_{0} x}\left(d_{1} \sin \alpha_{0} x+d_{2} \cos \alpha_{0} x\right) \\
& +e^{-\alpha x}\left(d_{3} \sin \alpha_{0} x+d_{4} \cos \alpha_{0} x\right)+\frac{q_{0} h_{0}}{\left(E_{1}+E_{2}\right) \eta^{\alpha}} \\
& \cdot\left[E_{1} t^{\alpha} E_{\alpha, \alpha+1}\left(\frac{E_{1} E_{2}}{\left(E_{1}+E_{2}\right) \eta^{\alpha}} \cdot t^{\alpha}\right)\right. \\
& \left.+\eta^{\alpha} E_{\alpha, 1}\left(-\frac{E_{1} E_{2}}{\left(E_{1}+E_{2}\right) \eta^{\alpha}} \cdot t^{\alpha}\right)\right] .
\end{aligned}
$$

4.4. Case Study. According to the geological conditions of the example coal mine panel, it has a length of $280 \mathrm{~m}$ and a width of $90 \mathrm{~m}$. The average mining height of the coal seam is $2.7 \mathrm{~m}$. The roof of the coal seam is sandstone with $4.5 \mathrm{~m}$ thickness, elastic modulus of $5.8 \mathrm{GPa}$, and Poisson's ratio of 0.27 . The load $q_{0}$ above the roof mainly comes from the weight of potential caving strata a, $q_{0}=2.0 \mathrm{MPa}$. The creep time $t$ is 24 hours. Considering the calculation time and accuracy, the first three terms of infinite series $m$ and $n$ in equation (37) and the first ten terms of infinite series $k$ in doubleparameter Mittag-Leffler function (16) are calculated. The boundary conditions of the beam are as follows:

$$
\begin{aligned}
w(x, t)_{x}=0 \\
x=L
\end{aligned}=0, \theta(x, t)_{x=0}^{x}=0 .
$$

By substituting boundary conditions (formulas in (38)) and the above parameters and creep parameters (from Table 1) into formulas (28) and (37), the parameters are as shown in Table 2.

The roof subsidence of elastic foundation and fractional foundation can be obtained as shown in Figure 7.

It can be seen from Figure 7 that the elastic foundation and the fractional viscoelastic foundation beam have the

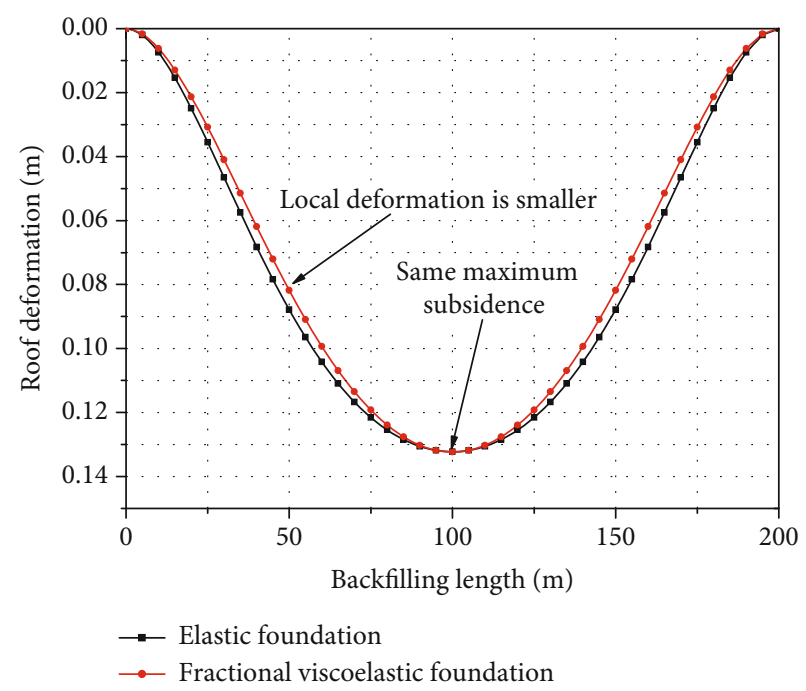

FIGURE 7: Roof subsidence of elastic foundation and fractional foundation.

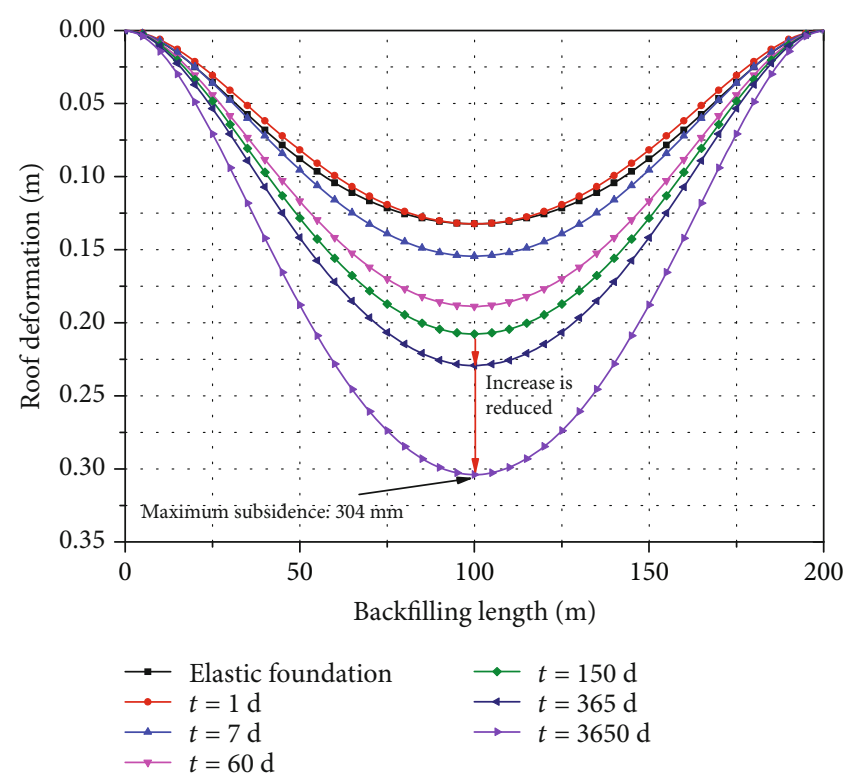

FIGURE 8: Roof subsidence with different time.

same deformation trend, and the maximum subsidence is the same. However, the local deformation of the fractional viscoelastic foundation is smaller, just because the fractional viscoelastic foundation has the higher global correlation. The roof subsidence calculated by the classic elastic foundation beam has been confirmed by many studies. It can be seen from the calculation of the final subsidence that the fractional viscoelastic foundation beam model is also reliable. 


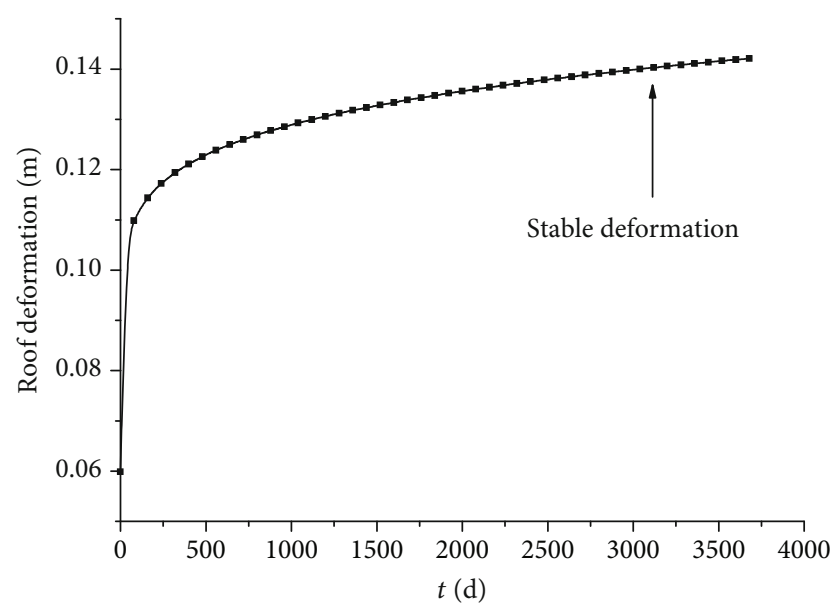

FIGURE 9: Relationship of maximum roof subsidence and time.

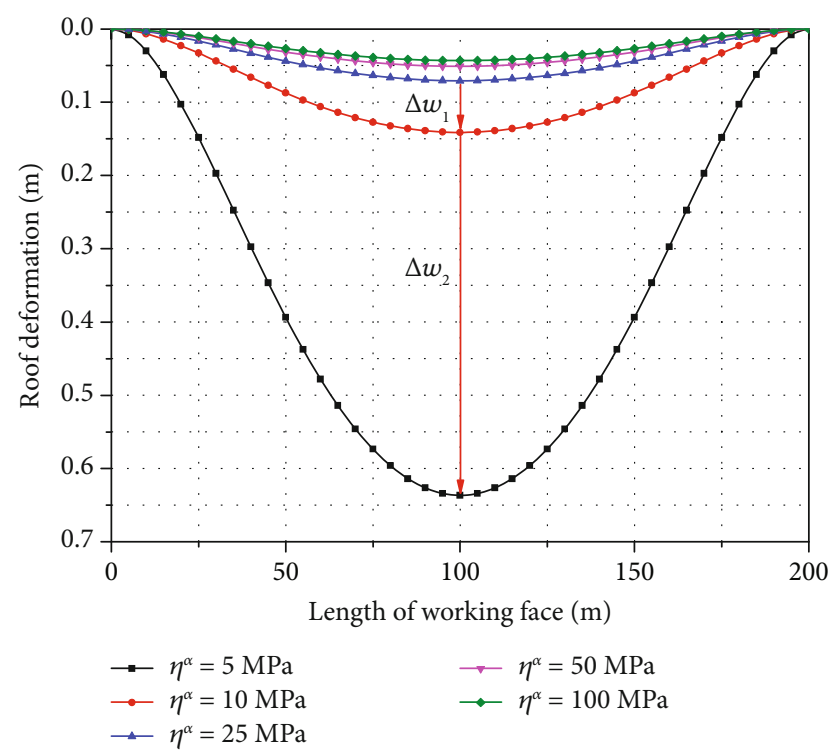

Figure 10: Roof subsidence with different time.

\section{Discussion}

5.1. Time Characteristics of Fractional Viscoelastic Foundation. Referring to the above for other parameters, the roof subsidence with different times can be obtained as shown in Figure 8. And the relationship of maximum roof subsidence and time is shown in Figure 9.

It can be seen from Figures 7 and 8 that as time increases, the roof deformation also increases accordingly. However, the increase in roof deformation gradually becomes smaller. The amount of roof subsidence increased from $154 \mathrm{~mm}$ in $7 \mathrm{~d}$ to $304 \mathrm{~mm}$ in 10 years, which shows an increase of $49.3 \%$. Compared with the elastic foundation and fractional viscoelastic foundation (10 years later), the roof deformation increased by $56.6 \%$.

5.2. Viscosity Characteristics of Fractional Viscoelastic Foundation. The roof subsidence with different viscosity coefficients can be obtained as shown in Figure 10. And the

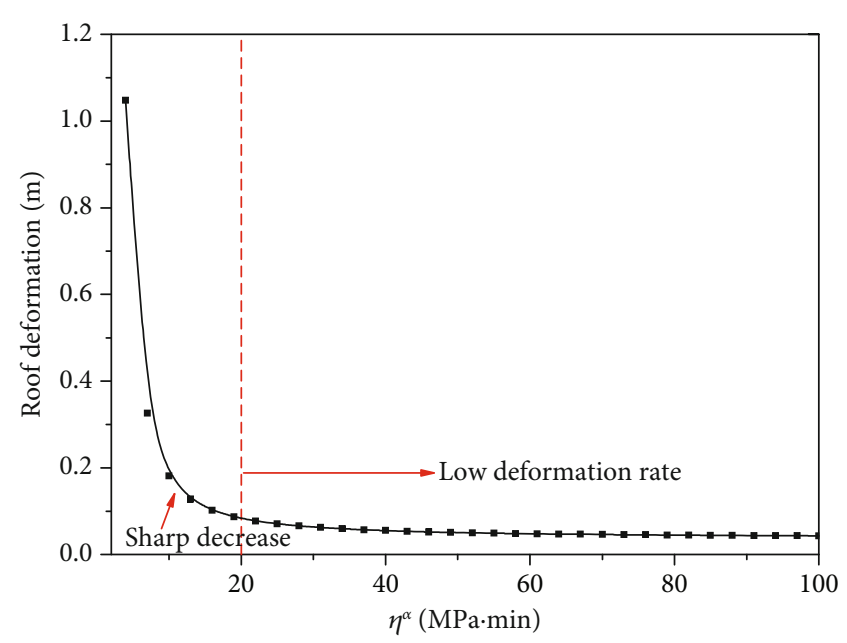

FIgURE 11: Relationship of maximum roof subsidence and time.

relationship of maximum roof subsidence and viscosity coefficient is shown in Figure 11.

It can be seen from Figures 10 and 11 that as the viscosity coefficient increases, the roof deformation decreases accordingly. However, the increase in roof deformation gradually becomes smaller, for example, $\Delta w_{1}$ which is smaller than $\Delta w_{2}$. The amount of roof subsidence reduced from $637 \mathrm{~mm}$ with a viscosity coefficient with $5 \mathrm{MPa}$ to $43.1 \mathrm{~mm}$ with a viscosity coefficient with $100 \mathrm{MPa}$, a proportional decrease of $93.2 \%$. Compared with the elastic foundation and fractional viscoelastic foundation (10 years later), the roof deformation increased by $56.6 \%$ as in Section 5.1 . It is also worth noting that the roof subsidence decreases sharply with the increase in coefficient of viscosity. When the viscosity coefficient is greater than $20 \mathrm{MPa}$-min, the effect of viscosity of the backfilling material on the roof control is limited. In other words, the viscosity coefficient of the backfilling material should reach $20 \mathrm{MPa}$-min in order to better control the sinking of the roof.

5.3. Fractional Order Characteristics of Fractional Viscoelastic Foundation. The roof subsidence with different fractional orders can be obtained as shown in Figure 12. And the relationship of maximum roof subsidence and fractional order is shown in Figure 13.

It can be seen from Figure 12 that as the fractional order increases, the roof deformation increases accordingly. However, the increase in roof deformation gradually becomes smaller, for example, $\Delta w_{1}$ is smaller than $\Delta w_{2}$. It can be also seen from Figure 13 that the relationship of maximum roof subsidence and fractional order is a nonlinear relationship. The fractional order can be obtained by fitting the experimental data, and the calculated roof subsidence is more accurate due to the fact that the fractional order is variable (moves in a changing trend).

\section{Conclusions}

The viscoelastic characteristics of gangue during creep deformation were analyzed. A fractional order viscoelastic 


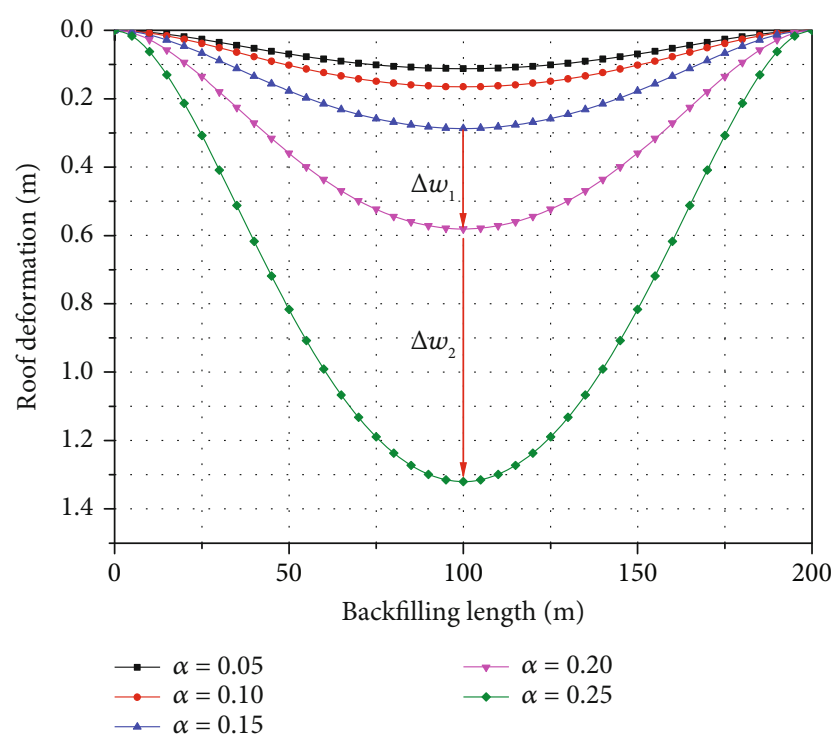

FIgURE 12: Roof subsidence with different fractional orders.

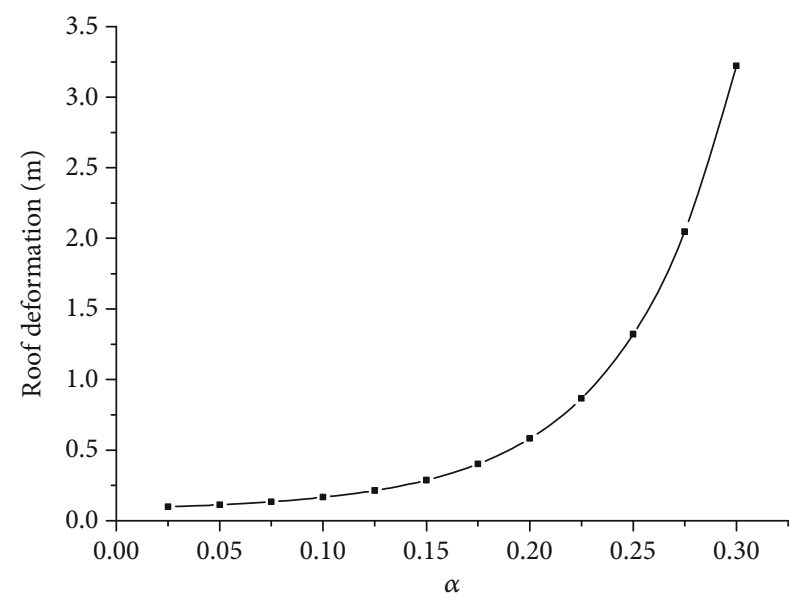

Figure 13: Relationship of maximum roof subsidence and fractional order.

foundation beam model was established; the differential equation of the fractional order viscoelastic foundation beam was obtained by Laplace transform; the deflection of classical elastic foundation and the fractional order viscoelastic foundation beam were compared and analyzed; and the time, viscosity, and order pair were discussed. The drawn conclusions are the following:

(1) The viscoelastic properties of gangue were analyzed through the graded creep test experiment. The deformation of gangue was divided into two stages of deceleration deformation and stable deformation. A high-precision fractional Poynting-Thomson creep model was established, and the parameters of gangue fractional Poynting-Thomson creep model were identified

(2) The viscoelastic foundation beam model was established by the gangue fractional Poynting-Thomson creep model, the deflection equation of the roof was obtained by Laplace transform, and the parameters of the viscoelastic foundation beam were obtained according to the boundary conditions. Compared with the classical elastic foundation beam model, the fractional viscoelastic foundation beam result is the most reliable

(3) According to the established viscoelastic foundation beam, the influence of time, viscosity, and order parameters on roof deformation was discussed. The fractional viscoelastic foundation beam can predict roof deformation according to time; appropriately increasing the viscosity of the backfilling material can be effective in the control of roof subsidence; and the nonlinear fractional order can improve the accuracy of the creep model, thereby improving the accuracy of the solution for the viscoelastic foundation beam

\section{Data Availability}

The data used to support the findings of this study are included in the article.

\section{Conflicts of Interest}

The authors declare no conflicts of interest regarding the publication of this paper.

\section{Acknowledgments}

This research was funded by the National Key R\&D Program of China (grant number 2018YFC0604704), the National Science Fund for Distinguished Young Scholars (grant number 51725403), the China Postdoctoral Science Foundation (grant number 2019M661990), and the Fundamental Research Funds for the Central Universities (grant number 2020QN05).

\section{References}

[1] J. X. Zhang, Q. Zhang, J. S. Spearing, X. X. Miao, S. Guo, and Q. Sun, "Green coal mining technique integrating miningdressing-gas draining-backfilling-mining," International Journal of Mining Science and Technology, vol. 27, no. 1, pp. 17-27, 2017.

[2] H. Wagner, "Deep mining: a rock engineering challenge," Rock Mechanics and Rock Engineering, vol. 4, 2019.

[3] D. Ma, H. Y. Duan, W. T. Liu, X. T. Ma, and M. Tao, "Watersediment two-phase flow inrush hazard in rock fractures of overburden strata during coal mining," Mine Water and the Environment, vol. 39, no. 2, pp. 308-319, 2020.

[4] H. Wang, W. Z. Chen, Q. B. Wang, and P. Q. Zheng, "Rheological properties of surrounding rock in deep hard rock tunnels and its reasonable support form," Journal of Central South University, vol. 23, 2016.

[5] H. W. Zhou, H. P. Xie, and J. P. Zuo, "Research progress of rock mechanical behavior under deep high ground stress," Advances in Mechanics, vol. 35, pp. 91-99, 2005. 
[6] D. Ma, J. X. Zhang, H. Y. Duan et al., "Reutilization of gangue wastes in underground backfilling mining: overburden aquifer protection," Chemosphere, vol. 264, no. 1, p. 128400, 2021.

[7] J. Zhang, M. Li, A. Taheri, W. Zhang, Z. Wu, and W. Song, "Properties and application of backfill materials in coal mines in China," Minerals, vol. 9, no. 1, p. 53, 2019.

[8] J. Li, Y. Huang, M. Qiao et al., "Effects of water soaked height on the deformation and crushing characteristics of loose gangue backfill material in solid backfill coal mining," Processes, vol. 6, no. 6, p. 64, 2018.

[9] M. Li, J. Zhang, Y. Huang, and N. Zhou, "Effects of particle size of crushed gangue backfill materials on surface subsidence and its application under buildings," Environmental Earth Sciences, vol. 76, no. 17, p. 603, 2017.

[10] P. Huang, S. Spearing, F. Ju, K. V. Jessu, Z. Wang, and P. Ning, "Control effects of five common solid waste backfilling materials on in situ strata of gob," Energies, vol. 12, no. 1, 2019.

[11] W. Guo, Y. Tan, T. Zhao, X. M. Liu, Q. H. Gu, and S. C. Hu, "Compression creep characteristics and creep model establishment of gangue," Geotechnical and Geological Engineering, vol. 34, no. 4, pp. 1193-1198, 2016.

[12] W. B. Chen, K. Liu, Z. Y. Yin, and J. H. Yin, "Crushing and flooding effects on one-dimensional time-dependent behaviors of a granular soil," International Journal of Geomechanics, vol. 20, no. 2, p. 04019156, 2020.

[13] W. A. Chen, Z. H. Chuan-ni, H. E. Peng, Z. H. Jian-wei, and L. I. Li, "Creep and particle breakage behavior of rockfill in triaxial compression testing," Journal of Civil, Architectural \& Environmental Engineering, vol. 33, no. 5, pp. 57-62, 2011.

[14] Z. Q. Song, Z. D. Cui, H. C. Xia, J. Q. Tang, and Z. J. Wen, “The fundemental theoretial and engineering research on the green safe no coal pillar mining model by mainly using coal gangue backfill," Journal of China Coal Society, vol. 35, no. 5, pp. 705-710, 2010.

[15] S. Li, Q. Zhang, and Z. Chen, "Experimental study of compaction creep model of broken rock," Journal of Mining World Express Volume, vol. 2, no. 4, 2013.

[16] M. Li, J. X. Zhang, and R. Gao, "Mechanical analysis of roof subsidence based on rheological properties of solid backfill materials," Tehnički vjesnik, vol. 23, no. 1, pp. 152-157, 2018.

[17] C. Wang, B. Shen, J. Chen et al., "Compression characteristics of filling gangue and simulation of mining with gangue backfilling: an experimental investigation," Geomechanics and Engineering, vol. 20, no. 6, pp. 485-495, 2020.

[18] T. Zhao, Z. Fu, and G. Li, "In situ investigation into fracture and subsidence of overburden strata for solid backfill mining," Arabian Journal of Geosciences, vol. 11, no. 14, p. 398, 2018.

[19] J. X. Zhang, H. Wang, and S. Chen, "Bearing capacity of backfill body and roof stability during strip coal pillar extracted with paste backfill," Geotechnical and Geological Engineering, vol. 36, no. 1, pp. 235-245, 2018.

[20] F. Ju, P. Huang, S. Guo, M. Xiao, and L. Lan, "A roof model and its application in solid backfilling mining," International Journal of Mining Science and Technology, vol. 27, no. 1, pp. 139-143, 2017.

[21] Y. Zhou, J. Zuo, C. Hu, G. Liu, Y. Shi, and H. Liu, "Strata movement model of filling coal mining based on twoparameter elastic foundation," Geotechnical and Geological Engineering, pp. 1-11, 2020.

[22] D. Chen, X. Wu, S. Xie et al., "Study on the thin plate model with elastic foundation boundary of overlying strata for back- fill mining," Mathematical Problems in Engineering, vol. 2020, 15 pages, 2020.

[23] X. Deng, J. Zhang, T. Kang, and X. Han, "Strata behavior in extra-thick coal seam mining with upward slicing backfilling technology," International Journal of Mining Science and Technology, vol. 26, no. 4, pp. 587-592, 2016.

[24] J. Chen, J. P. Du, W. S. Zhang, and J. X. Zhang, “An elastic base beam model of overlying strata movement during coal mining with gangue back-filling," Journal of China University of Mining \& Technology, vol. 41, no. 1, pp. 14-19, 2012.

[25] J. Z. Zhang, X. P. Zhou, and P. Yin, "Visco-plastic deformation analysis of rock tunnels based on fractional derivatives," Tunnelling and Underground Space Technology, vol. 85, pp. 209-219, 2019.

[26] H. W. Zhou, C. P. Wang, B. B. Han, and Z. Q. Duan, “A creep constitutive model for salt rock based on fractional derivatives," International Journal of Rock Mechanics and Mining Sciences, vol. 48, no. 1, pp. 116-121, 2011.

[27] D. Yin, H. Wu, C. Cheng, and Y. Q. Chen, "Fractional order constitutive model of geomaterials under the condition of triaxial test," International Design Engineering Technical Conferences and Computers and Information in Engineering Conference, vol. 37, no. 8, pp. 961-972, 2011.

[28] F. Wu, J. F. Liu, and J. Wang, "An improved Maxwell creep model for rock based on variable-order fractional derivatives," Environment and Earth Science, vol. 73, no. 11, pp. 6965-6971, 2015.

[29] B. R. Chen, X. J. Zhao, X. T. Feng, H. B. Zhao, and S. Y. Wang, "Time-dependent damage constitutive model for the marble in the Jinping II hydropower station in China," Bulletin of engineering geology and the environment, vol. 73 , no. 2, pp. 499515,2014

[30] R. L. Bagley, "Power law and fractional calculus model of viscoelasticity," AIAA Journal, vol. 27, no. 10, pp. 1412-1417, 1989.

[31] C. Zhang, Z. Zhu, S. Zhu et al., "Nonlinear creep damage constitutive model of concrete based on fractional calculus theory," Materials, vol. 12, no. 9, p. 1505, 2019.

[32] R. L. Bagley and P. J. Torvik, "A theoretical basis for the application of fractional calculus to viscoelasticity," Journal of Rheology, vol. 27, no. 3, pp. 201-210, 1983.

[33] K. S. Miller and B. Ross, An Introduction to the Fractional Calculus and Fractional Differential Equations, Wiley-Interscience, New York, USA, 1993.

[34] Y. J. Chen, C. L. Pan, P. Cao, and W. X. Wang, "A new mechanical model for soft rock rheology," Rock and Soil Mechanics, vol. 24, no. 2, pp. 209-214, 2003.

[35] D. Debernardi and G. Barla, "New viscoplastic model for design analysis of tunnels in squeezing conditions," Rock Mechanics and Rock Engineering, vol. 42, no. 2, pp. 259-288, 2009.

[36] Y. L. Zhao, Y. X. Wang, W. J. Wang, W. Wan, and J. Z. Tang, "Modeling of non-linear rheological behavior of hard rock using triaxial rheological experiment," International Journal of Rock Mechanics \& Mining Sciences. vol., vol. 93, pp. 66-75, 2017. 